\title{
Multimorbidity and the inequalities of global ageing: a cross-sectional study of 28 countries using the World Health Surveys
}

\author{
Sara Afshar ${ }^{1 *}$, Paul J. Roderick, Paul Kowal ${ }^{2,3}$, Borislav D. Dimitrov ${ }^{1}$ and Allan G. Hill ${ }^{4}$
}

\begin{abstract}
Background: Multimorbidity defined as the "the coexistence of two or more chronic diseases" in one individual, is increasing in prevalence globally. The aim of this study is to compare the prevalence of multimorbidity across low and middle-income countries (LMICS), and to investigate patterns by age and education, as a proxy for socio-economic status (SES).

Methods: Chronic disease data from 28 countries of the World Health Survey (2003) were extracted and inter-country socio-economic differences were examined by gross domestic product (GDP). Regression analyses were applied to examine associations of education with multimorbidity by region adjusted for age and sex distributions.

Results: The mean world standardized multimorbidity prevalence for LMICs was $7.8 \%$ (95 \% Cl, $7.79 \%$ - $7.83 \%$ ). In all countries, multimorbidity increased significantly with age. A positive but non-linear relationship was found between country GDP and multimorbidity prevalence. Trend analyses of multimorbidity by education suggest that there are intergenerational differences, with a more inverse education gradient for younger adults compared to older adults. Higher education was significantly associated with a decreased risk of multimorbidity in the all-region analyses.
\end{abstract}

Conclusions: Multimorbidity is a global phenomenon, not just affecting older adults in HICs. Policy makers worldwide need to address these health inequalities, and support the complex service needs of a growing multimorbid population.

Keywords: Multimorbidity, Ageing, Health inequalities, Epidemiological transition, Adult health

\section{Background}

The theory of epidemiological transition is grounded on the observed shift of disease burden from communicable to non-communicable disease (NCD) causes [1]. Whilst the debate about the role of population ageing in epidemiological transition continues, the demographic transition to older populations is also occurring across all regions, albeit with different patterns, determinants and rapidity. It has been shown that the ageing of populations is ongoing in both developed and developing countries although, the growth rate of older adults in low- and middle-income countries will remain significantly higher than in most high-income countries (HICs) for many

\footnotetext{
* Correspondence: sa2706@soton.ac.uk

'Academic Unit of Primary Care and Population Sciences, Faculty of Medicine, University of Southampton, Southampton General Hospital, Tremona Road, Southampton SO16 6YD, UK

Full list of author information is available at the end of the article
}

decades [2]. Multimorbidity is usually defined as the presence of two or more chronic diseases within an individual [3]. Although chronic disease factors are considered drivers of multimorbidity, the observed increase in multimorbidity is also related to both the demographic and epidemiologic transition. As the global population continues to grow in size, and becomes increasingly aged, there is an expectant increase in multimorbidity prevalence. Tackling multimorbidity as part of NCD burden remains one of the key challenges faced by the global community. In particular, health systems need to examine its socio-economic determinants in order to provide the most equitable health care to their populations and to drive NCD prevention.

Despite the growing recognition of the prevalence of multimorbidity amongst older adults, global prevalence studies have largely remained single-disease focused [4]. 
Few studies have reported national level estimates. Population prevalence studies in Spain and Germany suggest that multimorbidity prevalence is approximately $60 \%$ for people aged 65 years and above $[5,6]$. While the focus on older adults is common, multimorbidity also affects younger adults [7]. A study in Australia reported a multimorbidity prevalence of approximately $4 \%$ in adults aged $20-39$ years, $15 \%$ in the $40-59$ age group, and $39 \%$ in those aged 60 and older [8]. There are also contrasting associations by age and sex. Multimorbidity in HICs is reportedly more prevalent for individuals of higher ages, female sex, low income, and low education [9-11]. The outcomes of multimorbidity have been well documented in HICs, with multimorbidity being associated with reduced quality of life, decreased functional capacity, and reduced survival [12-14]. Studies have also shown the burden of multimorbidity and its relation to rising healthcare utilisation, cost and expenditure $[15,16]$. A comparison of the relationship between multimorbidity and socio-economic status (SES) show contrasting results for high, middle and low income countries. In Scotland, a high income country, multimorbidity has been found to be associated with lower SES [17]. In Bangladesh, a low income country - however, the wealthiest quintile of the population had an increased prevalence of multimorbidity [18]. And in studies examining its association with education, multimorbidity was more prevalent in those with lower educational levels in Canada (a HIC) [11]; while multimorbidity was less common among educated and employed persons in South Africa (an upper-middle income country) [19].

There have been no studies examining the age and socioeconomic distribution of multimorbidity (MM) in LMICs. The present study aims to establish the prevalence of MM in a range of LMICs, and to examine the variations of MM by age and education (as a proxy for SES).

\section{Methods}

\section{Study samples}

Publically available data from the WHO World Health Survey (WHS) was used, which is publicly available from the WHO. The World Health Surveys consists of crosssectional national studies, each of which follow a multistage clustering design to draw nationally representative samples of adults aged 18 years and older. The details of the survey procedures are described elsewhere [20, 21]. Seventy-one countries participated in the WHS between 2001 and 2004. Sample sizes varied between countries depending on feasibility and cost. Individual participants aged 18 years or above were randomly selected for interview. All surveys were implemented as face-to-face interviews; except for two countries, which used phone and mail-in interviews.

Of the seventy-one countries that participated in the WHS, eighteen countries were excluded from the analyses, as they did not complete the long version of the questionnaire covering chronic condition status; these were mostly countries from Western Europe. Countries were also excluded if the response rate to the chronic health questions was less than $90 \%$ (eleven countries) or if they did not include post-stratification weights (six countries). A minimum of four countries were randomly selected from each region for further analysis, resulting in a total of twentyeight of the remaining thirty-seven countries. Since the research questions aimed to address the differences between LMICs the majority of countries sampled were LMICs. Due to low response rates in certain regions, such as Africa, countries from Eastern Europe \& Central Asia were oversampled. We included one high income countries for comparison. In total, six countries were randomly selected from Africa; five countries from South-East Asia; four from South Asia; eight from Eastern Europe \& Central Asia; four from Central \& South America; and, one from Western Europe. Sampling weights were applied, as well as poststratification weights to account for non-response.

\section{Measures and variables}

In the WHS, chronic disease morbidity was defined by self-report, based on a set of six doctor diagnosed conditions. The self-reported conditions were assessed based on responses to the question, "Have you ever been diagnosed with...?" Previous studies have used different operational definitions of multimorbidity. Methodological differences, such as the number of chronic conditions to include in the count, result in a wide variability in prevalence estimates [7]. To prevent further discordance, multimorbidity is defined here as the presence of two or more chronic diseases, which is the most commonly used definition in prevalence studies [22]. A binary variable for multimorbidity was created on the presence of two or more of the six conditions: arthritis, angina or angina pectoris (a heart disease), asthma, depression, schizophrenia or psychosis, and diabetes.

The individual level socio-demographic variables of interest were age, sex and highest level of education completed. The residence of the individual, defined as living in either an 'urban' or 'rural' area, was also used in the description of the country characteristics. Two different age groupings were generated for different analyses: first, three age groupings for those 18-49 years, 50-64 years and 65+ years; and then by two groups for those younger than 55 (18-54 years) and those aged 55 years or older. The former was done to examine stratum specific differences, and the latter to examine generational differences. To examine generational differences, 55 years was taken as a cut point, representing a mid-way point within the WHS study population.

Level of education was used as a measure of countrylevel socioeconomic status (SES). 'Highest education level 
obtained' was collapsed from seven to four categories: (1) university or any higher education; (2) secondary school; (3) primary school; and, (4) less than primary school (including no formal education).

Inter-country socioeconomic differences were examined by using country estimates for GDP per capita. These were obtained from the United Nations Statistical Division records for 2003. Countries were then grouped according to the cut-offs for low- middle- and high-income based on the World Bank classification figures in 2003 [23].

\section{Statistical analysis}

Survey estimates were used to calculate prevalence measures and extract nationally representative samples, accounting for non-response. To obtain valid comparisons across the countries, age-standardised multimorbidity prevalence rates were calculated using the direct method with the WHO Standard Population (2000-2025) [24]. For the descriptive analyses, mean percentages were taken as an average across populations and normality of the distributions was tested using the Shapiro-Wilk test. We used non-parametric regression to produce a line of best fit, when comparing national estimates of multimorbidity with GDP. Individual countries were weighted by the survey size to produce regional estimates for comparisons of multimorbidity by age and education. Significance testing of the comparisons among independent samples was done by t-test or ANOVA while for those whose distributions deviated from the normal one - by the Wilcoxon rank-sum (for two variables) and

Table 1 Sample size, age, sex and urban/rural distributions for the selected World Health Survey Countries

\begin{tabular}{|c|c|c|c|c|c|c|c|c|}
\hline \multirow[t]{2}{*}{ WHS Countries $(n=28)$} & & \multirow[t]{2}{*}{ N Sample } & \multicolumn{3}{|c|}{ Age category, \% } & \multirow{2}{*}{$\begin{array}{l}\text { Sex, \% } \\
\text { Female }\end{array}$} & \multirow{2}{*}{$\begin{array}{l}\text { Residence, \% } \\
\text { Urban }\end{array}$} & \multirow{2}{*}{$\begin{array}{l}\text { National } \\
\text { income }\end{array}$} \\
\hline & & & $18-49$ & $50-64$ & $65+$ & & & \\
\hline \multirow[t]{6}{*}{ Africa } & Burkina Faso & 4948 & 82.8 & 12.7 & 4.5 & 52.8 & 17.8 & LIC \\
\hline & Ghana & 4165 & 80.1 & 15.3 & 4.6 & 50.9 & 45.6 & LIC \\
\hline & Kenya & 4640 & 87 & 9.6 & 3.4 & 51.2 & 39.9 & LIC \\
\hline & Morocco & 5000 & 78.6 & 15.7 & 5.7 & 50.5 & 57.5 & MIC \\
\hline & Namibia & 4379 & 78.5 & 13.4 & 8.1 & 53 & 33.2 & MIC \\
\hline & South Africa & 2629 & 79.7 & 15 & 5.3 & 52 & 56.3 & MIC \\
\hline \multirow[t]{4}{*}{ Central \& South America } & Brazil & 5000 & 74.7 & 18.5 & 6.8 & 51.5 & 83 & MIC \\
\hline & Dominican Republic & 5027 & 76.6 & 17 & 6.4 & 49.1 & 58.5 & MIC \\
\hline & Paraguay & 5288 & 80 & 14.8 & 5.2 & 50.4 & 56.7 & MIC \\
\hline & Uruguay & 2996 & 61.8 & 21.9 & 16.3 & 52.5 & 92.8 & MIC \\
\hline \multirow[t]{9}{*}{ Central Asia \& Eastern Europe } & Bosnia \& Herz & 1031 & 66.4 & 21.6 & 12 & 51.1 & 44.6 & MIC \\
\hline & Czech Republic & 949 & 57.8 & 27.4 & 14.8 & 52.1 & 73 & MIC \\
\hline & Estonia & 1021 & 55.5 & 26.9 & 17.6 & 55.4 & 69.7 & MIC \\
\hline & Georgia & 2950 & 60.9 & 23.8 & 15.3 & 53.3 & 51.5 & MIC \\
\hline & Hungary & 1419 & 57.3 & 26.6 & 16.1 & 53.2 & 64.9 & MIC \\
\hline & Kazakhstan & 4499 & 73.1 & 18.3 & 8.5 & 52.1 & 55.9 & LIC \\
\hline & Latvia & 929 & 55.2 & 27.7 & 17.1 & 55.4 & 66.5 & LIC \\
\hline & Ukraine & 2860 & 58.6 & 26.1 & 15.3 & 54.5 & 66.7 & MIC \\
\hline & Bangladesh & 5942 & 81.1 & 14.7 & 4.2 & 48.5 & 24.3 & LIC \\
\hline \multirow[t]{4}{*}{ South Asia } & Mauritius & 3968 & 73.6 & 18.7 & 7.7 & 50.8 & 43 & LIC \\
\hline & Pakistan & 6502 & 76.4 & 19.2 & 4.4 & 49.6 & 33.9 & MIC \\
\hline & Sri Lanka & 6805 & 71.5 & 20.6 & 7.9 & 47.9 & 20.6 & MIC \\
\hline & Laos & 4989 & 80 & 15 & 5 & 50.7 & 20.3 & LIC \\
\hline \multirow[t]{4}{*}{ South East Asia } & Malaysia & 6145 & 76.1 & 18.2 & 5.6 & 49.6 & 64.1 & LIC \\
\hline & Myanmar & 6045 & 77 & 16.5 & 6.5 & 51.1 & 29.1 & LIC \\
\hline & Nepal & 8822 & 78.1 & 16.8 & 5.1 & 49.5 & 15.2 & MIC \\
\hline & Philippines & 10083 & 79.3 & 15.7 & 5.1 & 50.4 & 61.4 & MIC \\
\hline \multirow[t]{2}{*}{ Western Europe } & Spain & 6373 & 59.2 & 22.1 & 18.7 & 51.5 & 76.8 & $\mathrm{HIC}$ \\
\hline & Mean & 4478.7 & 72 & 18.9 & 9 & 51.5 & 50.8 & \\
\hline
\end{tabular}


Table 2 Standardised multimorbidity prevalence by age category, with 2003 GDP per capita (in US\$)

\begin{tabular}{|c|c|c|c|c|c|}
\hline & \multicolumn{3}{|c|}{ Prevalence by age category (95 \% Cl) } & \multirow{2}{*}{$\begin{array}{l}\text { Prevalence } \\
(95 \% \mathrm{Cl})^{\mathrm{a}}\end{array}$} & \multirow{2}{*}{$\begin{array}{l}\text { GDP } \\
(\text { US } \$)^{b}\end{array}$} \\
\hline & $18-49$ & $50-64$ & $65+$ & & \\
\hline Myanmar & $1.30(1.0-1.60)$ & $1.9(1.0-2.7)$ & $3.1(1.7-4.5)$ & $1.7(1.4-2.0)$ & 200.0 \\
\hline Nepal & $10.1(9.3-10.9)$ & $24.8(22.2-27.5)$ & $30.2(26.2-34.1)$ & $15.2(14.3-16.0)$ & 264.0 \\
\hline Burkina Faso & $4.8(4.1-5.5)$ & $9.7(7.2-12.2)$ & $13.0(9.0-16.9)$ & $6.3(5.6-7.0)$ & 332.0 \\
\hline Laos & $2.5(2.0-3.0)$ & $6.5(4.6-8.4)$ & $5.3(2.7-7.8)$ & $3.6(3.1-4.1)$ & 358.0 \\
\hline Bangladesh & $2.9(2.4-3.4)$ & $10.9(8.6-13.2)$ & $12.6(9.2-16.1)$ & $6.8(6.1-7.5)$ & 419.0 \\
\hline Kenya & $2.1(1.6-2.5)$ & $3.2(1.8-4.6)$ & $11.5(8.1-14.9)$ & $4.2(3.6-4.8)$ & 440.0 \\
\hline Pakistan & $3.4(2.9-3.9)$ & $8.7(6.8-10.6)$ & $14.8(11.1-18.5)$ & $4.9(4.3-5.4)$ & 597.0 \\
\hline Ghana & $2.0(1.5-2.5)$ & $4.4(2.8-5.9)$ & $6.6(4.3-9.0)$ & $3.6(3.0-4.2)$ & 603.0 \\
\hline Georgia & $4.0(3.0-5.1)$ & $15.0(11.8-18.1)$ & $27.1(23.3-30.9)$ & $9.6(8.4-10.8)$ & 874.0 \\
\hline Sri Lanka & $1.2(0.9-1.5)$ & $6.6(5.2-8.1)$ & $9.6(7.1-12.0)$ & $3.9(3.4-4.3)$ & 968.0 \\
\hline Philippines & $3.8(3.4-4.3)$ & $12.0(10.3-13.7)$ & $17.2(14.1-20.3)$ & $7.1(6.6-7.7)$ & 1016.0 \\
\hline Ukraine & $3.3(2.4-4.2)$ & $17.8(14.6-20.9)$ & $31.6(27.1-36.1)$ & $10.0(8.8-11.1)$ & 1049.0 \\
\hline Paraguay & $3.2(2.7-3.8)$ & $9.4(7.2-11.5)$ & $12.0(9.0-15.0)$ & $5.7(5.1-6.4)$ & 1159.0 \\
\hline Morocco & $3.0(2.5-3.6)$ & $13.6(11.1-16.1)$ & $17.5(13.8-21.1)$ & $6.4(5.7-7.1)$ & 1684.0 \\
\hline Kazakhstan & $1.5(1.1-1.9)$ & $10.1(7.9-12.3)$ & $45.1(37.4-52.8)$ & $8.5(7.6-9.4)$ & 2109.0 \\
\hline Bosnia \& Herz & $2.3(1.0-3.5)$ & $11.7(7.3-16.0)$ & $30.2(22.7-37.7)$ & $7.6(5.9-9.3)$ & 2182.0 \\
\hline Dominican Republic & $4.5(3.7-5.2)$ & $15.7(13.0-18.5)$ & $18.5(14.9-22.1)$ & $7.2(6.4-8.0)$ & 2210.0 \\
\hline Namibia & $4.5(3.7-5.2)$ & $11.9(8.9-14.9)$ & $17.7(13.4-21.9)$ & $7.9(7.0-8.8)$ & 2489.0 \\
\hline Brazil & $8.1(7.1-9.0)$ & $21.4(18.4-24.4)$ & $28.0(23.7-32.3)$ & $13.4(12.4-14.5)$ & 3039.0 \\
\hline South Africa & $5.0(3.9-6.0)$ & $21.6(16.6-26.6)$ & $30.1(20.6-39.7)$ & $11.2(9.8-12.5)$ & 3589.0 \\
\hline Uruguay & $4.1(3.2-5.0)$ & $12.4(9.7-15.1)$ & $17.0(13.5-20.5)$ & $7.3(6.3-8.2)$ & 3622.0 \\
\hline Malaysia & $2.0(1.6-2.5)$ & $9.6(7.8-11.4)$ & $14.6(11.2-17.9)$ & $5.6(5.0-6.2)$ & 4607.0 \\
\hline Mauritius & $3.3(2.6-3.9)$ & $15.8(12.8-18.7)$ & $19.3(14.9-23.6)$ & $7.8(6.9-8.6)$ & 4830.0 \\
\hline Latvia & $2.7(1.1-4.3)$ & $16.0(10.7-21.2)$ & $35.6(28.1-43.0)$ & $9.6(7.5-11.7)$ & 4872.0 \\
\hline Estonia & $6.2(4.0-8.4)$ & $14.4(9.9-18.8)$ & $34.4(26.8-41.9)$ & $11.5(9.4-13.6)$ & 7350.0 \\
\hline Hungary & $7.8(5.8-9.9)$ & $27.9(22.5-33.3)$ & $32.3(26.2-38.3)$ & $15.0(13.0-17.1)$ & 8237.0 \\
\hline Czech Republic & $3.5(1.8-5.1)$ & $11.6(7.2-16.0)$ & $39.4(30.8-48.0)$ & $9.4(7.4-11.4)$ & 9339.0 \\
\hline Spain & $3.1(2.5-3.8)$ & $15.3(13.3-17.3)$ & $22.6(20.5-24.6)$ & $7.8(7.1-8.5)$ & 21035.0 \\
\hline
\end{tabular}

World Mean Prevalence 7.8 (7.8-7.8)

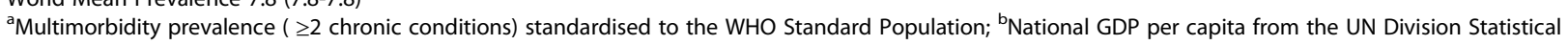
Division, 2003

Kruskal-Wallis (for more than two variables) tests. 'Prevalence ratios' of multimorbidity by education were calculated with the reference category being primary school education completion. Univariable models were fitted to analyse the association of both sex and age with multimorbidity. For the multivariable analyses, data were pooled at regional level. A random effects logistic regression model was fitted for the regional analysis, to account for the hierarchical nature of the data within countries and regions. Odds ratios (OR) and $95 \%$ confidence intervals $(\mathrm{CI})$ are presented, with $p<$ 0.05 taken as statistically significant, unless stated otherwise. All analyses were done using Stata version 12. Confidence intervals have been calculated based on recommendations for crude and age-specific rates [25].

\section{Results}

Individual country characteristics are described in Table 1. Socio-demographic characteristics, including age and sex distributions are shown. Population age structures differed across the countries $(p<0.05)$, with a mean percentage of $9.0 \%$ (95\% CI, 7.1 - 11.0) in those aged $65+$ compared to $72.0 \%(95 \% \mathrm{CI}, 68.4-75.7)$ in those aged 18-49. Age-standardisation of rates were calculated to account for these population distribution differences. The mean percentage of those living in rural areas was $49.2 \%$ (95 \% CI, $41.3-57.1$ ) compared to $50.8 \%$ in urban areas (95\% CI, 42.9 -58.7), although the difference was not significant. Countries in Central Asia \& Eastern Europe region had a higher proportion of individuals in the $65+$ age category $($ mean $=14.6 \%$; $95 \%$ CI, $12.5-16.7)$ 
compared to the African region (mean $=5.3 \%$; $95 \% \mathrm{CI}$, $4.1-6.4 ; p<0.05)$.

Individual morbidity estimates suggest that arthritis is the most common condition across the WHS countries, with mean prevalence of $12.0 \%$ (95\% CI, 11.8 - 12.2). The mean prevalence for depression, angina, asthma, diabetes and schizophrenia, respectively, were $6.7 \%$, $7.5 \%, 5.0 \%, 4.0 \%$ and $0.9 \%$ [see Additional file 1]. Multimorbidity prevalences by country are shown in Table 2 . Both age-specific prevalences and age standardized prevalence are shown for each country. The mean world standardized prevalence for LMICs was 7.8 \% (95\% CI, $6.5-9.1)$ and the range was $1.7 \%$ (95\% CI, 1.4-2.0) to $15.2 \%(14.3-16.0)$. The mean multimorbidity prevalence significantly increased with age in all countries $(p<0.05)$; $3.8 \%$ (95 \% CI, 3.0 - 4.6) for age 18-49, $12.8 \%$ (95 \% CI, $10.5-15.2)$ for $50-64$; and $21.3 \%$ (95\% CI, 17.1 - 25.5) for $65+$.

Figure 1 shows national levels of multimorbidity by country GDP per capita. There was a positive association between multimorbidity prevalence and GDP per capita (from GDP per capita of $\$ 200-\$ 10,000)$. Above $\$ 10,000$ the line flattens: Spain had a relatively low multimorbidity prevalence given their high GDP per capita.

Figure 2 shows the prevalence ratios of multimorbidity across socioeconomic groups, stratified into younger and older adults. Amongst the younger adults, across all regions, there was a distinct negative socioeconomic gradient, with the highest burden on the least educated. In Western Europe there appeared to be a wider variation between SES categories, compared to SE Asia and Africa. Amongst older adults, there was less variation between SES categories, compared to the younger adults. However, there was still a distinct negative gradient in Western Europe, with the highest burden on the least educated. South-East Asia on the other hand has a positive gradient, with the highest burden on the most educated.

Both univariable and multivariable analyses are shown in Tables 3 and 4. Univariable and multivariable analyses at the country level are shown in Table 3, showing the sociodemographic correlates of age, sex and education. Age was significantly associated with multimorbidity in

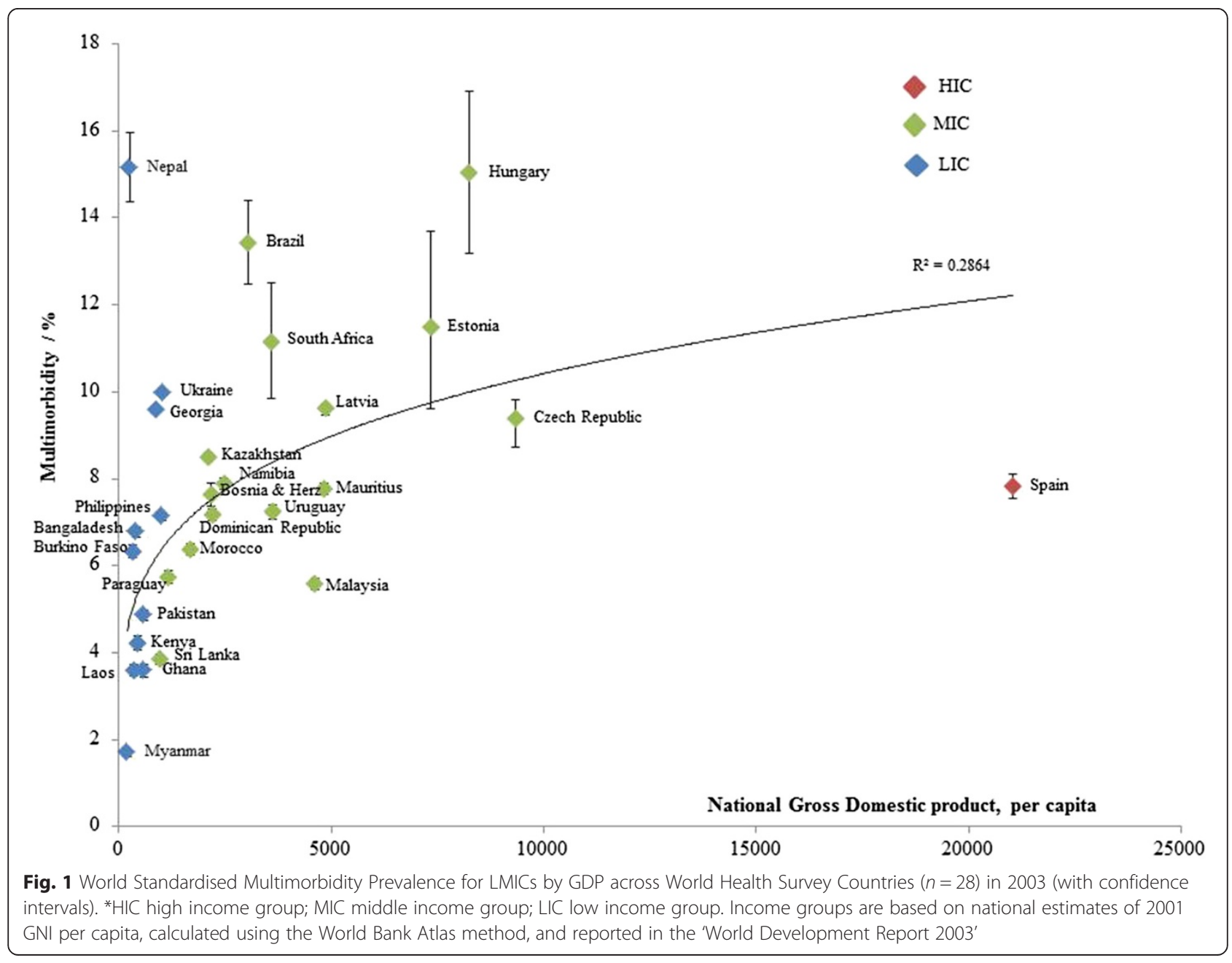



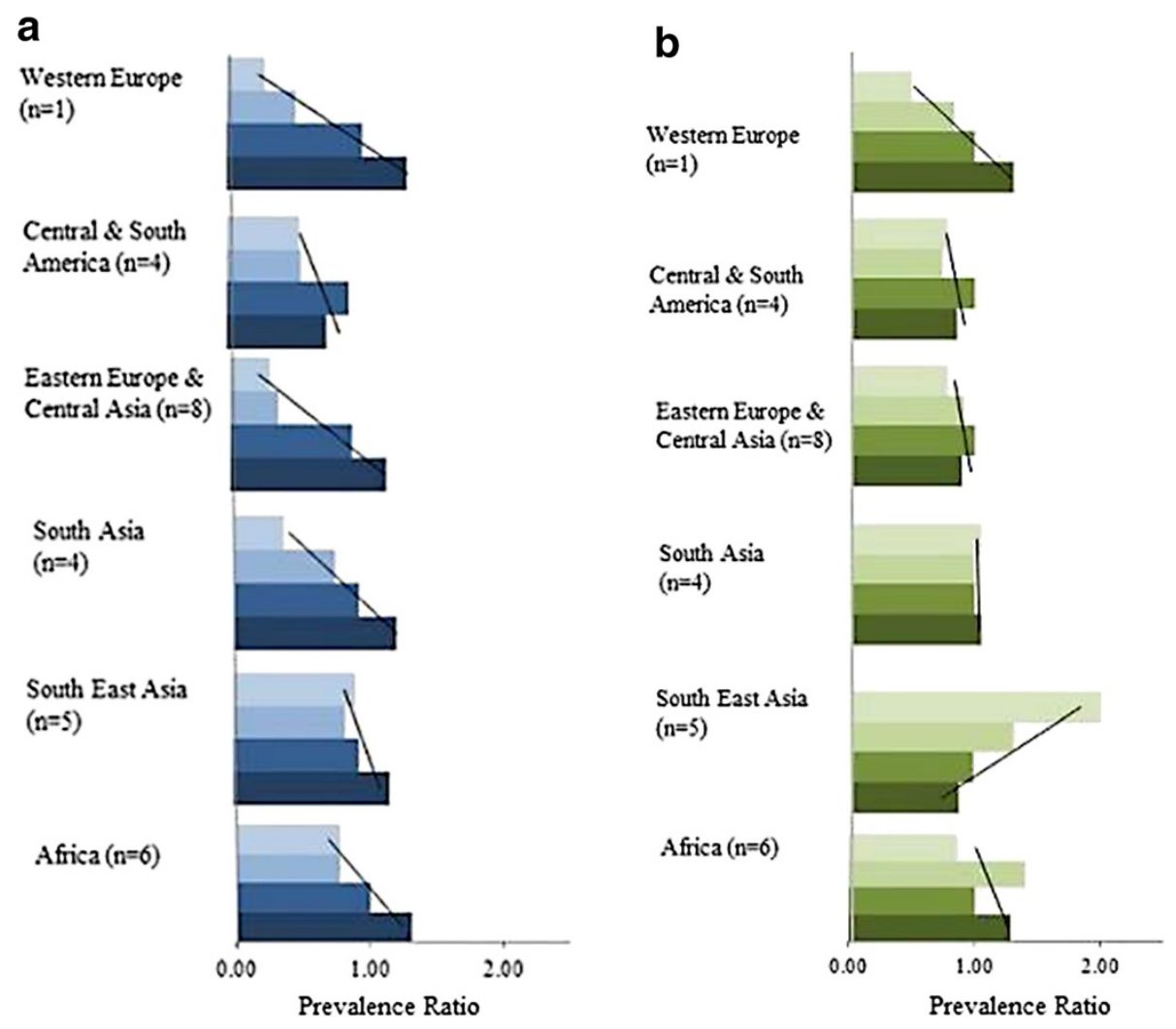

Fig. 2 a: The socioeconomic gradient of multimorbidity by regions, for age category $1(<55)$. b: The socioeconomic gradient of multimorbidity by regions, for age category 2 ( $\geq 55$ ). The lightest shade represents the first category (higher education achieved). The darkest shade represents final category (less than primary school education achieved). Multimorbidity prevalence ratios are based on the prevalence of multimorbidity in the third category, set at 1

all countries. Sex was significantly associated with multimorbidity in all but seven countries. Multimorbidity was associated with education in the univariable analyses, but was not significant when adjusted for both age and sex, except for certain education categories in Bangladesh, Brazil, Hungary, Mauritius, Namibia and Spain; which were all consistent with an inverse relationship.

Similar to the country level, age and sex were both significantly associated with multimorbidity in all regions (Table 4). When adjusted for age and sex, the lowest education category was significantly associated with a higher risk of multimorbidity in Africa and Western Europe; and higher education categories were significantly associated with a decreased risk of multimorbidity in South Asia and Western Europe. Adjusted for age, sex, country and region, the 'all region' model suggests an overall negative education gradient.

\section{Discussion}

The subject of multimorbidity is of growing interest, in part, due to the ageing of all populations. Internationally, there is still limited evidence on the prevalence and social determinants of multimorbidity, particularly in LMICs. This is the first study to describe global patterns of multimorbidity and to compare prevalence across different countries including LMICs. There are a few notable findings. Firstly, despite the variation in multimorbidity prevalence the mean world standard prevalence for LMICs was 7.8 \% (95 \% CI, 6.5 - 9.1), so even in LMICs the multimorbidity prevalence was quite high. Secondly, multimorbidity prevalence was positively associated with country GDP per capita. There was however a non-linear relationship; our one HIC Spain had a low multimorbidity relative to per capita GDP. These results suggest an influence of other factors which may include, but are not limited to, more freedom to make better lifestyle choices and better social conditions [26]. In comparison to Spain, the Eastern European countries have relatively high multimorbidity prevalence. Historically, Eastern Europe has had poorer population health outcomes relative to their western counterparts following the fall of communism in 1990. Such health outcomes were markedly influenced by exposure to risk factors, such as tobacco smoking and alcohol consumption [27-29]. Thirdly, multimorbidity 
Table 3 Effect of age, sex and education on multimorbidity by country: Odds ratios in univariable, multivariable analysis

\begin{tabular}{|c|c|c|c|c|c|c|c|c|c|}
\hline & \multicolumn{2}{|c|}{ Age (OR) 18-49 as reference } & \multirow{2}{*}{$\begin{array}{l}\text { Sex (OR) Male } \\
\text { as reference }\end{array}$} & \multicolumn{3}{|c|}{ Education (OR) primary school as reference } & \multicolumn{3}{|c|}{ Education (AOR) } \\
\hline & $50-64$ & $65+$ & & $<$ primary & Secondary & higher & $<$ primary & secondary & higher \\
\hline Burkina Faso & $2.2^{*}$ & $3.0^{*}$ & $0.7^{* * * *}$ & 1.1 & 0.5 & 1.1 & 0.9 & 0.5 & 1.1 \\
\hline Bangladesh & $4.1^{*}$ & $4.9^{*}$ & 0.9 & 1.1 & 0.7 & $0.4^{* * *}$ & 0.8 & 0.7 & $0.4^{* * *}$ \\
\hline Bosnia \& Herz & $5.7^{*}$ & $18.7^{*}$ & $0.4^{* * *}$ & $3.0^{* *}$ & 0.6 & $\$$ & 1.0 & 1.0 & $\$$ \\
\hline Brazil & $3.1^{*}$ & $4.4^{*}$ & $0.5^{*}$ & $1.6^{*}$ & $0.6^{*}$ & 0.8 & 1.2 & $0.8^{* * *}$ & 0.8 \\
\hline Czech Republic & $3.7^{*}$ & 18.1 & 0.6 & 2.3 & $0.3^{* * *}$ & 0.4 & 1.3 & 0.7 & 0.7 \\
\hline Dominican Republic & $4.0^{*}$ & $4.8^{*}$ & $0.3^{*}$ & $2.0^{* *}$ & 0.7 & 0.9 & 1.3 & 0.6 & 0.8 \\
\hline Estonia & $2.6^{*}$ & $8.0^{*}$ & $0.6^{* *}$ & 1.6 & 0.8 & 0.6 & 0.9 & 1.3 & 0.9 \\
\hline Georgia & $4.2^{*}$ & $8.8^{*}$ & $0.6^{*}$ & 1.9 & 0.7 & 0.8 & 2.0 & 2.3 & 2.9 \\
\hline Ghana & $2.2^{*}$ & $3.5^{*}$ & $0.6^{* *}$ & 1.2 & 3.0 & 1.2 & 0.9 & 0.3 & 1.2 \\
\hline Hungary & $4.6^{*}$ & $5.6^{*}$ & $0.5^{*}$ & 2.9 & $0.4^{*}$ & $0.2^{* * *}$ & $3.4^{* * *}$ & 0.8 & $0.5^{* * *}$ \\
\hline Kazakhstan & $7.4^{*}$ & $54.2^{*}$ & $0.5^{*}$ & 0.3 & $0.2^{*}$ & $0.1^{* * *}$ & 0.5 & 1.1 & 0.8 \\
\hline Kenya & $1.6^{*}$ & $6.2^{*}$ & 1.0 & $2.3^{*}$ & 1.7 & 2.5 & 1.4 & 1.8 & 2.4 \\
\hline Laos & $2.7^{*}$ & $2.2^{*}$ & 0.9 & 1.5 & 0.5 & 0.2 & 1.3 & 0.5 & 0.3 \\
\hline Latvia & $6.9^{*}$ & $20.0^{*}$ & $0.4^{* *}$ & 1.6 & 0.9 & 1.0 & 0.7 & 1.7 & 1.3 \\
\hline Malaysia & $5.2^{*}$ & $8.2^{*}$ & 0.8 & $1.8^{*}$ & $0.5^{*}$ & $0.5^{*}$ & 1.1 & 0.8 & 0.8 \\
\hline Mauritius & $5.6^{*}$ & $7.1^{*}$ & $0.6^{*}$ & $2.8^{*}$ & $0.4^{*}$ & $0.4^{* * *}$ & 1.3 & $0.5^{*}$ & 0.4 \\
\hline Morocco & $5.0^{*}$ & $6.8^{*}$ & $0.6^{* * *}$ & 1.4 & 0.5 & 0.4 & 0.6 & 0.6 & 0.7 \\
\hline Myanmar & $1.4^{*}$ & $2.4^{*}$ & $0.5^{* *}$ & 0.9 & 1.4 & 1.3 & 0.6 & 1.5 & 1.2 \\
\hline Namibia & $2.7^{*}$ & $4.3^{*}$ & $0.6^{* *}$ & $2.2^{*}$ & 0.7 & 1.2 & $1.7^{* * *}$ & 0.8 & 1.4 \\
\hline Nepal & $2.9^{*}$ & $0.8^{*}$ & 1.0 & $1.3^{*}$ & 0.9 & 1.4 & 0.9 & 0.9 & 1.4 \\
\hline Pakistan & $2.7^{*}$ & $4.9^{*}$ & $0.5^{* *}$ & 1.4 & 0.6 & 1.1 & 0.9 & 0.6 & 1.1 \\
\hline Paraguay & $3.0^{*}$ & $4.1^{*}$ & $0.3^{*}$ & 1.2 & 1.0 & 1.0 & 0.8 & 1.1 & 1.0 \\
\hline Philippines & $3.4^{*}$ & $5.2^{*}$ & $0.6^{*}$ & $1.7^{*}$ & 0.8 & 1.1 & 1.3 & 1.1 & 1.3 \\
\hline South Africa & $5.3^{*}$ & $8.3^{*}$ & $0.6^{*}$ & $2.4^{*}$ & 0.8 & 0.5 & 1.6 & 1.1 & 0.7 \\
\hline Spain & $5.6^{*}$ & $9.1^{*}$ & $0.6^{*}$ & $1.8^{*}$ & $0.4^{*}$ & $0.2^{*}$ & $1.4^{* * *}$ & $0.8^{* * *}$ & $0.4^{* *}$ \\
\hline Sri Lanka & $5.9^{* * *}$ & $8.8^{* * *}$ & 0.7 & 1.2 & $0.5^{* * *}$ & 0.3 & 0.9 & 0.9 & 0.5 \\
\hline Ukraine & $6.4^{* * *}$ & $13.7^{* * *}$ & $0.4^{* * *}$ & 0.7 & 0.5 & 0.3 & 0.6 & 1.4 & 1.3 \\
\hline Uruguay & $3.3^{* * *}$ & $4.8^{* * *}$ & $0.5^{* * *}$ & $2.0^{* *}$ & 0.8 & 0.7 & 1.4 & 1.0 & 0.9 \\
\hline
\end{tabular}

${ }^{*} p$-value ${ }^{* *}<0.05 ;{ }^{* *}<0.01 ; *<0.001 ;(\mathrm{OR})$ Unadjusted odds ratio; (AOR) Adjusted odds ratios in multivariable analysis: all countries adjusted for age and sex. $\$$ indicates no observations within the category. For Bosnia \& Herzegovina the categories of secondary and higher education were combined for both univariable and multivariable analyses

was significantly associated with age across all countries including LMICs. This finding has been found consistently across several studies [9, 17, 30-34]. Fourthly, multimorbidity as defined here, is also not limited to older adults, but affects younger adults in LMICs. This association of multimorbidity with age, however, might reflect the type of condition included in the disease count and their age of onset [35]. Fifthly, trend analyses of multimorbidity and education suggest a transgenerational difference: with a transition to a more negative education gradient is observed for younger adults compared to older adults in LMICs. Our 'all region' model also suggests an inverse relationship between multimorbidity and education. These findings are consistent with what has been found in other studies in HICs [17, 32]. Finally, there are notable gender differences in multimorbidity: the female sex being associated with higher multimorbidity. This is a common observation in morbidity studies, often attributed to greater use of health services and disease diagnosis [33]. Though other studies also suggest the role of other factors, including behavioural and psychosocial $[34,36]$. Other studies suggest that clustering patterns of multimorbidity differ for male and females; for example, the cardiometabolic cluster was reportedly more common in males. This occurrence could be due to known differences in physiology, such as the protective effect of female hormones on CVD [37]. 
Table 4 Effect of age, sex and socioeconomic status on multimorbidity: Odds ratios in univariable, multivariable analysis using a random effects model

\begin{tabular}{|c|c|c|c|c|c|c|c|c|}
\hline & \multicolumn{5}{|l|}{ Univariable } & \multirow{2}{*}{\multicolumn{3}{|c|}{$\frac{\text { Multivariable }}{\text { Education }(\mathrm{AOR})^{\S}}$}} \\
\hline & \multirow{3}{*}{$\begin{array}{l}\text { Age }(\mathrm{OR}) \\
<55 \text { years as reference } \\
\geq 55\end{array}$} & \multirow{3}{*}{$\begin{array}{l}\text { Sex (OR) } \\
\text { Male as reference }\end{array}$} & \multicolumn{3}{|c|}{ Education (OR) } & & & \\
\hline & & & \multicolumn{3}{|c|}{ primary school as reference } & \multirow[b]{2}{*}{$<$ primary } & \multirow[b]{2}{*}{ secondary } & \multirow[b]{2}{*}{ higher } \\
\hline & & & $<$ primary & secondary & higher & & & \\
\hline Africa & $3.3^{*}$ & $0.6^{*}$ & $1.8^{*}$ & 0.8 & 0.7 & $1.2^{* *}$ & 0.9 & 0.8 \\
\hline Central \& South America & $3.0^{*}$ & $0.4^{*}$ & $1.5^{*}$ & $0.7^{*}$ & $0.8^{* * *}$ & 1.1 & $0.8^{* * *}$ & 0.8 \\
\hline Eastern Europe \& Central Asia & $6.0^{*}$ & $0.6^{*}$ & $1.4^{* * *}$ & $0.5^{*}$ & $0.5^{*}$ & 1.0 & 1.0 & 0.9 \\
\hline South Asia & $4.1^{*}$ & $0.7 *$ & $1.7^{*}$ & $0.6^{*}$ & $0.6^{* *}$ & 1.2 & $0.7^{*}$ & $0.6^{* *}$ \\
\hline South East Asia & $3.3^{*}$ & $0.8^{*}$ & $1.4^{*}$ & $0.8^{*}$ & 0.9 & 1.1 & 0.9 & 1 \\
\hline Western Europe & $6.0^{*}$ & $0.5^{*}$ & $1.6^{*}$ & $0.4^{*}$ & $0.2^{*}$ & $1.3^{* *}$ & $0.7^{*}$ & $0.4^{*}$ \\
\hline All regions (MV adjusted for region) & $3.7^{*}$ & $0.6^{*}$ & $1.5^{*}$ & $0.7^{*}$ & $0.6^{*}$ & $1.2^{*}$ & $0.9^{* * *}$ & $0.8^{*}$ \\
\hline
\end{tabular}

$p$-value ${ }^{* * *}<0.05 ;{ }^{* *}<0.01 ; *<0.001 ;{ }^{\$}$ Regional multivariable analyses adjusted for age, sex and country; (OR) Unadjusted odds ratio; (AOR) Adjusted odds ratios in multivariable analysis adjusted for age, sex and country

One of the study aims was to examine the variations of multimorbidity by SES here with education as a proxy. Our descriptive analyses of education show that both regional differences and generational differences exist for adults with multimorbidity. In Western Europe and Eastern Europe \& Central Asia, there was wider variation in prevalence ratios between SES categories, compared to other regions. And for adults aged $<55$ years, the gradient was always negative, with one exception of older adults in South-East Asia. This suggests that in South-East Asia there might have been an intergenerational reversal in the socioeconomic gradient of multimorbidity. Such results have also been found in studies on obesity where transitional economies are experiencing a reversal in socioeconomic gradient thus resulting in a similar gradient to HICs [38].

The global-level multivariable analyses show a negative association of multimorbidity with education. Results from Western Europe (Spain) suggest a significantly negative education gradient of multimorbidity in HICs. In Africa, there is also a significantly negative education gradient in multimorbidity. The education gradient in Africa, despite most countries in this region being LMICs, is similar to the Western Europe region. These results are contrary to the Bangladesh study, which sampled 850 individuals (60 years and above) in a rural area and reported a direct association of multimorbidity with SES [18]. The SES index in their study, however, was based on household assets. Alternative measures of SES may lead to different results. One study in rural Uganda reports maternal education to be a better predictor of health; whereas other studies explore the use of permanent income $[39,40]$.

\section{Strengths and limitations}

This study provides novel data on multimorbidity prevalence in nationally representative population samples using a consistent set of methods measures across multiple countries. Being the first of its kind, one of its major strengths is the availability and comparability of the data across all a wide range of countries using the World Health Surveys which were developed for this reason.

The study has few limitations which, even if not undermining its contributions and potential impact, should be also mentioned. Firstly, prevalence estimates were based on a limited set of conditions [7]. The chronic conditions included in the WHS were chosen to reflect health system coverage [41]. The conditions had to be amenable to self-report and reflect a known burden or prevalence globally. The choice of conditions should correspond to those with greater prevalence in older populations (prevalence for asthma, for instance, is more typically higher in older children and younger adulthood). Secondly, the study presents crosssectional data from 2003. Further investigations should use current or recent data, as well as longitudinal data, to ascertain changing patterns over time. Thirdly, only countries with a greater than $90 \%$ response rate to health status questions on chronic disease were sampled, which meant that a number of lower income countries, where response rates were low, were excluded from the analyses. There was also low representation from HICs, as these countries largely did not complete the chronic disease questions. As such the use of Spain only - to represent Western Europe was a limitation. Fourthly, these results were based on self-reported measures, which may result in disease underreporting and potential bias [42-44]. One study notes that self-reporting leads to underreporting, particularly amongst the poor, which dampen the gradients [45]. It may be that health literacy and service access impact prevalence based on self-report for countries at different levels of economic development. Self-reported diagnosis can be further validated by 
auxiliary symptom-reporting questions included in the survey, such as the Rose questionnaire used for angina, or through clinical assessment [46]. National GDP is generally correlated with healthcare system investment and potentially healthcare access, which might affect the interpretation of the results. Spain, however, had low multimorbidity relative to national GDP despite having a relatively good healthcare system access. In order to understand the relationship between a country's development and multimorbidity as an appropriate health outcome, further studies are needed: with a fuller accounting of confounding, modifying and mediating elements. Finally the use of education as a proxy for SES has been debated despite its wide use in population health research $[47,48]$. There is evidence to suggest that after conditioning for the effect of socioeconomic status, measured by household income or assets, education has an independent and substantial effect on health outcomes [49].

\section{Conclusion}

Multimorbidity is common in LMICs and significantly associated with age. There is an inverse country association of multimorbidity with education, which indicates an inequity of disease burden. The negative gradient of multimorbidity with education is already occurring and more marked in the younger generation. It may reflect the proliferation of several key risk factors for these chronic conditions including unhealthy behaviours. The recent UN World Summit addressed the common risk factors of NCDs to be tackled with urgent priority; namely tobacco use, unhealthy diet, harmful use of alcohol and physical inactivity [50]. Weak health systems and governance will not be able to support the care needs resulting from the complexities of a multimorbid population. Better coordination and support through informed policy and planning of health care systems is needed to support the transition required for health systems to address future care needs. Furthermore, there is a need to increase activities and expand measures to reduce the modifiable risk factors that are driving multimorbidity prevalence.

\section{Additional file}

Additional file 1: Shows the crude morbidity prevalence of chronic disease by country and region.

\section{Competing interests}

The authors declare that they do not have competing interests.

\section{Authors' contributions}

SA has made significant contributions through the conception, data analysis, interpretation and drafting of the manuscript. PR, BDD and AH have made contributions to the conception, analysis and interpretation of results; as well as the re-drafting of the manuscript. PK has made contributions to the accuracy of information, revising of the manuscript and final approval before submission.

\section{Authors' information}

This work is part of an ongoing doctoral research programme. SA is a PhD student and PR, BDD and AH are academic supervisors at the Academic Unit of Primary Care and Population Sciences and Co-Chairs and members of the Strategic Research group (USRG) for Population Health at the University of Southampton (www.southampton.ac.uk/populationhealth); PK is the WHO co-PI of WHO's SAGE (www.who.int/healthinfo/sage/en/), Senior Research Fellow at the University of Newcastle's Priority Research Centre for Gender, Health and Ageing, and is an external advisor to the doctoral study.

\section{Acknowledgements}

We would like to thank Mr Scott Harris and Dr Kandala Ngianga for their support during the statistical analysis.

\section{Funding}

This work was supported by the World Health Organization and the US National Institutes of Health.

\section{Author details}

${ }^{1}$ Academic Unit of Primary Care and Population Sciences, Faculty of Medicine, University of Southampton, Southampton General Hospital, Tremona Road, Southampton SO16 6YD, UK. ${ }^{2}$ University of Newcastle Research Centre for Gender, Health and Ageing, Newcastle, NSW, Australia.

'World Health Organization's Study on global AGEing and adult health (SAGE), Geneva, Switzerland. ${ }^{4}$ Academic Unit of Social Statistics and Demography, Faculty of Social and Human Sciences, University of Southampton, Southampton, UK.

Received: 13 March 2015 Accepted: 1 July 2015

Published online: 13 August 2015

\section{References}

1. Omran A. The epidemiologic transition: a theory of the epidemiology of population change. 1971. Milbank Quarterly. 2005;83(4):731-57.

2. Preparing for an Aging World. The Case for Cross-National Research. Washington DC: The National Academies Press; 2001.

3. Almirall J, Fortin M. The coexistence of terms to describe the presence of multiple concurrent diseases. Journal of Comorbidity. 2013;3(1):4-9.

4. Lim SS, Vos T, Flaxman AD, Danaei G, Shibuya K, Adair-Rohani H et al. A comparative risk assessment of burden of disease and injury attributable to 67 risk factors and risk factor clusters in 21 regions, 1990-2010: a systematic analysis for the Global Burden of Disease Study 2010. The Lancet. 2012;380(9859):2224-60.

5. Garin N, Olaya B, Perales J, Moneta MV, Miret M, Ayuson-Mateos JL, Haro JM. Multimorbidity Patterns in a National Representative Sample of the Spanish Adult Population. PLoS ONE. 2014; doi:10.1371/journal.pone.0084794.

6. Kirchberger I, Meisinger C, Heier M, Zimmermann AK, Thorand B, Autenrieth CS et al. Patterns of Multimorbidity in the Aged Population. Results from the KORA-Age Study. PLOS ONE. 2012; doi:10.1371/journal.pone.0030556.

7. Fortin M, Hudon C, Haggerty J, van den Akker M, Almirall J. Prevalence estimates of multimorbidity: a comparative study of two sources. BMC Health Services Research. 2010;10:111.

8. Taylor AW, Price K, Gill TK, Adams R, Pilkington R, Carrangis N et al. Multimorbidity - not just an older person's issue. Results from an Australian biomedical study. BMC Public Health. 2010;10:718.

9. Ward BW, Schiller JS. Prevalence of multiple chronic conditions among US adults: estimates from the National Health Interview Survey, 2010. Prev Chronic Dis. 2010;10:E65.

10. Agborsangaya CB, Lau D, Lahtinen M, Cooke T, Johnson JA. Multimorbidity prevalence and patterns across socioeconomic determinants: a crosssectional survey. BMC Public Health. 2012;12:201.

11. St John PD, Tyas SL, Menec V, Tate R. Multimorbidity, disability, and mortality in community-dwelling older adults. Can Fam Physician. 2014;60(5):e272-80.

12. Fortin M, Bravo G, Hudon C, Lapointe L, Almirall J, Dubois MF, et al. Relationship between multimorbidity and health-related quality of life of patients in primary care. Qual Life Res. 2006;15(1):83-91. 
13. Dy SM, Pfoh ER, Salive ME, Boyd CM. Health-related quality of life and functional status quality indicators for older persons with multiple chronic conditions. J Am Geriatr Soc. 2013;61(12):2120-7.

14. Marengoni A, von Strauss E, Rizzuto D, Winblad B, Fratiglioni L. The impact of chronic multimorbidity and disability on functional decline and survival in elderly persons. A community-based, longitudinal study. J Intern Med. 2009;265(2):288-95.

15. Steiner CA, Friedman B. Hospital Utilization, Costs, and Mortality for Adults With Multiple Chronic Conditions, Nationwide Inpatient Sample, 2009. Prev Chronic Dis. 2013;10:120292.

16. Van den Bussche H, Schon G, Kolonko T, Hansen H, Wegscheider K, Glaeske $\mathrm{G}$, et al. Patterns of ambulatory medical care utilization in elderly patients with special reference to chronic diseases and multimorbidity - Results from a claims data based observational study in Germany. BMC Geriatrics. 2011;11:54.

17. Barnett K, Mercer SW, Norbury M, Watt G, Wyke S, Guthrie B. Epidemiology of multimorbidity and implications for health care, research, and medical education: a cross-sectional study. The Lancet. 2012;380(9836):37-43.

18. Khanam MA, Streatfield PK, Kabir ZN, Qiu C, Cornelius C, Wahlin A Prevalence and patterns of multimorbidity among elderly people in rural Bangladesh: a cross-sectional study. J Health, Population Nutri. 2011;29(4):406-14.

19. Alaba O, Chola L. The social determinants of multimorbidity in South Africa. Int J Equity Health. 2013;12:63.

20. Moussavi S, Chatterji S, Verdes E, Tandon A, Patel V, Ustun B. Depression, chronic diseases, and decrements in health: results from the World Health Surveys. Lancet. 2007;370(9590):851-8.

21. Ustun TB, Chatterji S, Villanueva M, Bendib L, Celik C, Sandana R et al. Chapter 57: WHO Multi-Country Survey Study on Health and Responsiveness 2000-2001. In: Murray CJL, David BE, editors. Health Systems Performance Assessment. Geneva: World Health Organization; 2003. p. 761

22. Smith SM, Soubhi H, Fortin M, Hudon C, O'Dowd T. Managing patients with multimorbidity: systematic review of interventions in primary care and community settings. BMJ. 2012;345:e5205.

23. The World Bank. World Development Report 2003: Sustainable Development in a Dynamic World - Transforming Insitutions, Growth and Quality of Life. Washington DC, USA: World Bank; 2003

24. Ahmad OB, Boschi-Pinto C, Lopez AD, Murray CJL, Lozano R, Inoue M. Age Standardisation of rates: A New WHO Standard. Geneva, Switzerland: GPE Discussion Paper Series; No.31, 2001.

25. Anonymous. Guidelines for Using Confidence Intervals for Public Health Assessment. (Washington State Department of Health. 2012; Accessed online at www.doh.wa.gov/Portals/1/Documents/5500/ConflntGuide.pdf on 24/09/2014)

26. Sen A. Development as freedom. Oxford, UK: OUP; 2001.

27. Leon DA, Chenet L, Shkolnikov VM, Zakharov S, Shapiro J, Rakhmanaova G et al. Huge variation in Russian mortality rates 1984-94: artefact, alcohol, or what? Lancet. 1997;350:383-88.

28. Gilmore A, McKee M. Moving east: how the transnational tobacco companies gained entry to the emerging markets of the former Soviet Union. Part I: Establishing cigarette imports. Tobacco Control. 2004;13:143-50.

29. Men T, Brennan P, Boffetta P, Zaridze D. Russian mortality trends for 1991-2001: analysis by cause and region. BMJ. 2003;327:964.

30. Lochner KA, Cox CS. Prevalence of Multiple Chronic Conditions among Medicare Beneficiaries, United States, 2010. Prev Chronic Dis. 2013;10:120137.

31. Rizza A, Kaplan V, Senn O, Rosemann T, Bhend H, Tandjung R. Age- and gender-related prevalence of multimorbidity in primary care: the swiss fire project. BMC Fam Pract. 2012;13:113.

32. Orueta JF, Nuno-Solinis R, Garcia-Alvarez A, Alonso-Moran E. Prevalence of multimorbidity according to the deprivation level among the elderly in the Basque Country. BMC Public Health. 2013;13:918.

33. Mustard CA, Kaufert $P$, Kozyrskyj A, Mayer T. Sex differences in the use of health care services. N Engl J Med. 1998;338(23):1678-83.

34. Green CA, Pope CR. Gender, psychosocial factors and the use of medical services: a longitudinal analysis. Soc Sci Med. 1999;48(10):1363-72.

35. Poblador-Plou B, van den Akker M, Vos R, Calderon-Larranaga A, Metsemakers J, Prados-Torres A. Similar Multimorbidity Patterns in Primary Care Patients from Two European Regions: Results of a Factor Analysis. PLoS ONE. 2014; doi:10.1371/journal.pone.0100375.

36. Chun $\mathrm{H}$, Khang $\mathrm{YH}$, Kim IH, Cho SI. Explaining gender differences in illhealth in South Korea: the roles of socio-structural, psychosocial, and behavioral factors. Soc Sci Med. 2008;67(6):988-1001.
37. Abad-Diez JM, Calderon-Larranaga A, Poncel-Falco A, Poblador-Plou B, Calderon-Meza JM, Sicras-Mainar A et al. Age and gender differences in the prevalence and patterns of multimorbidity in the older population. BMC Geriatrics. 2014;14:75

38. Selmi A, Chandola T, Friel S, Nouraei R, Shipley MJ, Marmot MG. Interaction between Education and Household Wealth on the Risk of Obesity in Women in Egypt. PLoS ONE. 2012; doi:10.1371/journal.pone.0039507.

39. Po JYT, Finlay JE, Brewster MB, Canning D. Estimating Household Permanent Income from Ownership of Physical Assets, in Working Paper Series. Harvard University: Center for Population \& Development Studies; 2012.

40. Wamani H, Tylleskar T, Astrom AN, Tumwine JK, Peterson S. Mothers' education but not fathers' education, household assets or land ownership is the best predictor of child health inequalities in rural Uganda. Int J Equity Health. 2004;3:9

41. Ustun TB, Chatterji S, Mechbal A, Murray CJL. Chapter 58: The World Health Surveys. In: Murray CJL, David BE, editors. Health Systems Performance Assessment. Geneva: World Health Organization; 2003. p. 761.

42. Harlow SD, Linet MS. Agreement between questionnaire data and medical records. The evidence for accuracy of recall. Am J Epidemiol. 1989;129(2):233-48.

43. Bush T, Miller SR, Golden A, Hale WE. Self-report and medical record report agreement of selected medical conditions in the elderly. Am J Public Health. 1989;79(11):1554-6.

44. Horwitz RI. Comparison of epidemiological data from multiple sources. J Chron Dis. 1986;79:1554-6.

45. Vellakkal S, Subramanian SV, Millet C, Basu S, Stuckler D, Ebrahim S. Socioeconomic Inequalities in Non-Communicable Diseases Prevalence in India: Disparities between Self-Reported Diagnoses and Standardized Measures. PLoS ONE. 2013; doi:10.1371/journal.pone.0068219.

46. Rose G, McCartney P, Reid DD. Self-administration of a questionnaire on chest pain and intermittent claudication. Br J Prev Soc Med. 1977;31(1):42-8.

47. Desai S, Alva S. Maternal education and child health: Is there a strong causal relationship? Demography. 1998;35(1):71-8.

48. Basu AM. Maternal education, fertility and child mortality: Disentangling verbal relationships. Health Transition Review. 1994;4:207-15.

49. Baker DP, Leon J, Smith Greenaway EG, Collins J, Movit M. The Education effect on population health: a reassessment. Popul Dev Rev. 2011;37(2):307-32.

50. Nations U. Political declaration of the high-level meeting of the General Assembly on the prevention and control of non-communicable diseases (Document A/RES/66.2). in High Level Meeting on Prevention and Control of Non-communicable Diseases. New York: United Nations; 2011. Available from: http://www.un.org/en/ga/ncdmeeting2011.

\section{Submit your next manuscript to BioMed Central and take full advantage of:}

- Convenient online submission

- Thorough peer review

- No space constraints or color figure charges

- Immediate publication on acceptance

- Inclusion in PubMed, CAS, Scopus and Google Scholar

- Research which is freely available for redistribution 